\title{
VARIATION OF RARE EARTH ELEMENTS (REES) IN THE SULU AND CELEBES SEAS OF MALAYSIAN WATERS DURING PMSE 09' EXPEDITION USING ANALYTICAL AND CHEMOMETRIC TECHNIQUES
}

\author{
G. Adiana ${ }^{1}$, H. Juahir ${ }^{1, *}$, N. A. M. Shazili ${ }^{2}$, B. Joseph ${ }^{2}$ and A. F. I. Yusra ${ }^{1}$ \\ ${ }^{1}$ East Coast Environmental Research Institute (ESERI), Universiti Sultan Zainal Abidin, Gong \\ Badak Campus, 21030 Kuala Nerus, Terengganu, Malaysia \\ ${ }^{2}$ Institute of Oceanography and Environment (INOS), Universiti Malaysia Terengganu, 21030 \\ Kuala Nerus, Terengganu, Malaysia
}

Published online: 08 August 2017

\begin{abstract}
This study provides a dataset of rare earth elements (REEs) in the seawater of Sulu and Celebes Seas of Malaysian waters during the PMSE 09' expedition, which was conducted to define the pattern of REEs in both seas. Samples were collected, filtered and pre-concentrated on-board ship then analyzed by using ICP-MS. Generally, the spatial distribution pointed out a high concentration of REEs in vicinities with high number of local settlements and Borneo Island riverine flush-outs. The chemometric analysis has showed the competition of binding sites between REEs and salt ions. The REEs normalized against NPDW evidence the influence of South China Sea waters lessen with the increase in water depth. Additionally, the studied area shows that both seas are affected by local river drainage from Borneo Island, Indonesia and Philippine archipelagos.
\end{abstract}

Keywords: dissolved REEs; particulate REEs; Sulu Sea; Celebes Sea; environmetric analysis.

Author Correspondence, e-mail: hafizanjuahir@unisza.edu.my doi: http://dx.doi.org/10.4314/jfas.v9i2s.28 


\section{INTRODUCTION}

According to International Union of Pure and Applied Chemistry, IUPAC [1], rare earth elements (REEs) are 15 lanthanide elements with atomic number from 57 (Lanthanum) to 71 (Lutetium). In addition, Scandium (atomic number of 21) and Yttrium (atomic number of 39) also are classified as REEs since they shared similar chemical properties and have a tendency to present in the REEs ore deposits. Their existence in the environment is not really rare but normally they exist together in a group and difficult to separate from each other. Recently, REEs are vital for high technology applications such as electronics, network and communications and health care [2]. For example, REEs are essential in the production of phosphor, a fluorescent substance used in the fluorescent lamps production [3] as well as the usage of Gd complexes such as (Gd-DTPA) ${ }^{2}$ as a magnetic resonance contrast agents [4]. Such activities evidence the increasing of REEs discharge into the environment namely the water column. Even though REEs are not priority pollutants such as mercury, arsenic and cadmium but at an optimum concentration, it may cause an adverse effect to human and environmental health. However, REEs are an excellent geochemical, archaeology and disturbances tracer in the environment [5-8]. For instance, REEs reflect the geochemical processes which recorded the volcanic-hydrothermal activities through Europium (Eu) anomaly as Eu(III) can be reduced to Eu(II) at high temperature and pressure [9-10].

Sulu Sea is a marginal sea, encompassed by the Borneo Island in the north-east and the Philippine Islands in the southern-west. This deep basin which covers approximately 250,000 $\mathrm{km}^{2}$ area [11] is isolated from South China Sea, Celebes Sea and Philippine Sea by shallow sills of less than $400 \mathrm{~m}$ depth [11-13]. The obstruction caused by the sills provides a pure marine water column system of Sulu Sea on the vertical profile of physical, chemical and biological processes. Similar to Sulu Sea, the Celebes Sea also possesses its own unique deep sea characteristics. It is a semi closed marginal sea surrounded by Borneo, Mindanao, Sulu, Sangihe and Sulawesi Islands. Celebes Sea consists of $4800 \mathrm{~m}$ to $5400 \mathrm{~m}$ water depth, covering approximately $380,000 \mathrm{~km}^{2}$ area $[11,14]$.

During the period of $18^{\text {th }}$ June 2009 to $2^{\text {nd }}$ August 2009, the National Oceanography Directorate under Ministry of Science, Technology and Innovation of Malaysia funded a 
scientific research expedition with the cooperation of National Hydrographic Centre, Royal Malaysian Navy (RMN). Known as Prime Marine Scientific Expedition 2009 (PMSE 09'), this research expedition covered Malaysian waters of the South China, Sulu and Celebes Seas using RMN's survey vessel, KD Perantau. The area covered was divided into four sections namely Leg 1 (Port Klang to Labuan Island), Leg 2 (Labuan Island to Kota Kinabalu), Leg 3 (Kota Kinabalu to Tawau) and Leg 4 (Tawau to Kota Kinabalu). Several researchers from the local universities and Malaysian government agencies joined this expedition. The rationale of this expedition was to investigate the marine environment processes corresponding to the Coral Triangle Initiative in order to maintain the health and productivity of the area. The present study was only covered the Leg 3 and Leg 4 areas encompassing Malaysian waters of Sulu and Celebes Seas off Kota Kinabalu to Tawau coasts. This region was chosen for the present study to investigate the impact of rapid increase of human population, industrial and tourism activities along the Borneo Island coastal water towards the Sulu and Celebes Seas. Goals of this research were to define the level of REEs in the Borneo Island coastal waters as well as to define the correlation of water parameters with existing REEs spatially and via vertical profiling.

\section{MATERIAL AND METHODS}

\subsection{Sample Collection}

Laboratory wares were cleaned up and soaked in $10 \%$ nitric acid for a few days, followed by rinsing thoroughly using Mili-Q water prior to sample collection and laboratory analysis. Water samples were collected from 37 stations covering the Sulu and Celebes Seas of Malaysian waters (Fig. 1). 


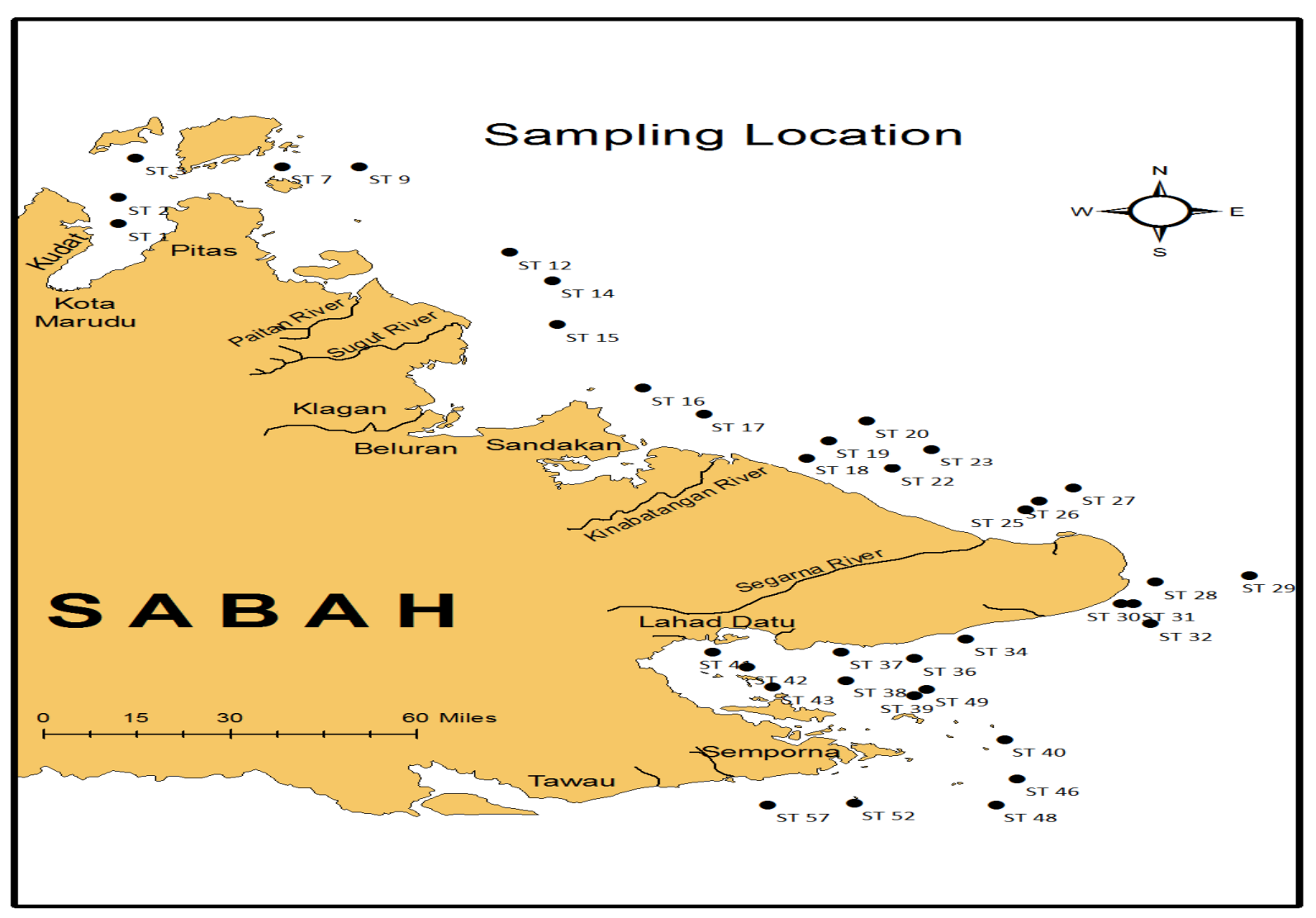

Fig.1. Sampling locations

Water samples were collected using 1 liter Mercos all Teflon bottle sampler at possibly four water layers, i.e. $1 \mathrm{~m}, 25 \mathrm{~m}, 50 \mathrm{~m}$ and $100 \mathrm{~m}$ depending on the area's water depth. Mercos water sampler was released into the sea and drawn using man-power due to keep the sampler as clean as possible. Due to that, the study was only able to collect water samples up to $100 \mathrm{~m}$ deep for the REEs analysis. Seawater samples was immediately filtered using $0.45 \mu \mathrm{m}$ acid washed polytetrafluoroethylene (PTFE) membranes and on-line pre-concentrated using Chelex-100 columns under the class-100 clean laminar flow hood in order to separate dissolved and particulate samples [15-16]. Dissolved samples (water samples passed through the PTFE membrane) were then preserved with concentrated nitric acid whereas particulate samples retained on the PTFE membranes were stored in air-tight plastic container separately for particulate metals. Both samples were sealed in polyethylene bags and kept in a chiller under $4^{\circ} \mathrm{C}$, prior transportation to the laboratory for analysis. The physical parameters were measured in-situ during the sampling trip using well inspected CTD Seabird.

\subsection{Laboratory Analysis}

Dissolved REEs were eluted from Chelex-100 resin under class-100 laminar flow hood bench 
whereas particulate samples were digested under Ethos Plus microwave heating using a mixture of concentrated Suprapur acids in closed Teflon vessels [17-19]. Both treated samples were analyzed using Inductively Coupled Plasma Mass Spectrometry (ICPMS) Elan 9000. All REEs namely Scandium (Sc), Yttrium (Y), Lanthanum (La), Cerium (Ce), Praseodymium (Pr), Neodymium (Nd), Samarium (Sm), Europium (Eu), Gadolinium (Gd), Thorium (Th), Terbium (Tb), Dysprosium (Dy), Holmium (Ho), Erbium (Er), Thulium (Tm), Ytterbium (Yb) and Lutetium $(\mathrm{Lu})$ were measured in both dissolved and particulate samples except for Prometium $(\mathrm{Pm})$ since all of its isotopes are radioactive. Methods used to treat both type of samples are in accordance with Nearshore Seawater Reference Material for Trace Metals (CASS-5) and Estuarine Sediment (NIST 1646a). This is to ensure that accurate and precise methodologies were used in the study. Blanks were carried out using Mili-Q water and acid-washed PTFE membrane filters for dissolved and particulate phase respectively. REEs recovery result recorded was in the range of $88 \%$ to $103 \%$ for dissolved phase and $90 \%$ to $104 \%$ for particulate phase.

\subsection{Data and Statistical Analysis}

\subsubsection{Principal Component Analysis}

Principal component analysis (PCA) is a multivariate statistical technique, which has been widely used to classify data by defining the relationship between measured variables. PCA uses variables reductioin technique to minimize variables observed. This analysis can be expressed as:

$Z_{i j}=a_{i 1} x_{1 j}+a_{i 2} x_{2 j}+a_{i 3} x_{3 j}+a_{i m} x_{m j}$

where $z$ : measured value of a variable, $a$ : component loading, $x:$ component score, $i:$ sample number and $m$ : total number of factors.

Normally, PCA uses factor analysis (FA) in order to interpret a complex and large dataset as it will define similarities between variables [21-23]. The application of varimax rotation in PCA is advisable for a better interpretation of principal components (PCs). PCs with eigenvalues greater than 1 are significant to generate new variables namely varimax factors (VFs). According to [24], VF coefficient is considered as strong, moderate and weak significant 
factor loadings with correlations greater than $0.75,0.75-0.50$ and $0.50-0.30$ correspondingly. In the present study, PCA/FA for REEs group was applied to 22 normalized variables.

\section{RESULTS}

Fig. 2 shows the range of dissolved and particulate REEs in the Sulu and Celebes Seas of Malaysian waters. The lower and upper lines of the box represent the minimum and maximum value of the data set respectively. The horizontal line drawn within the box represents the median of the data set whereas the two vertical lines extended from the box represent the standard deviation of the data set.
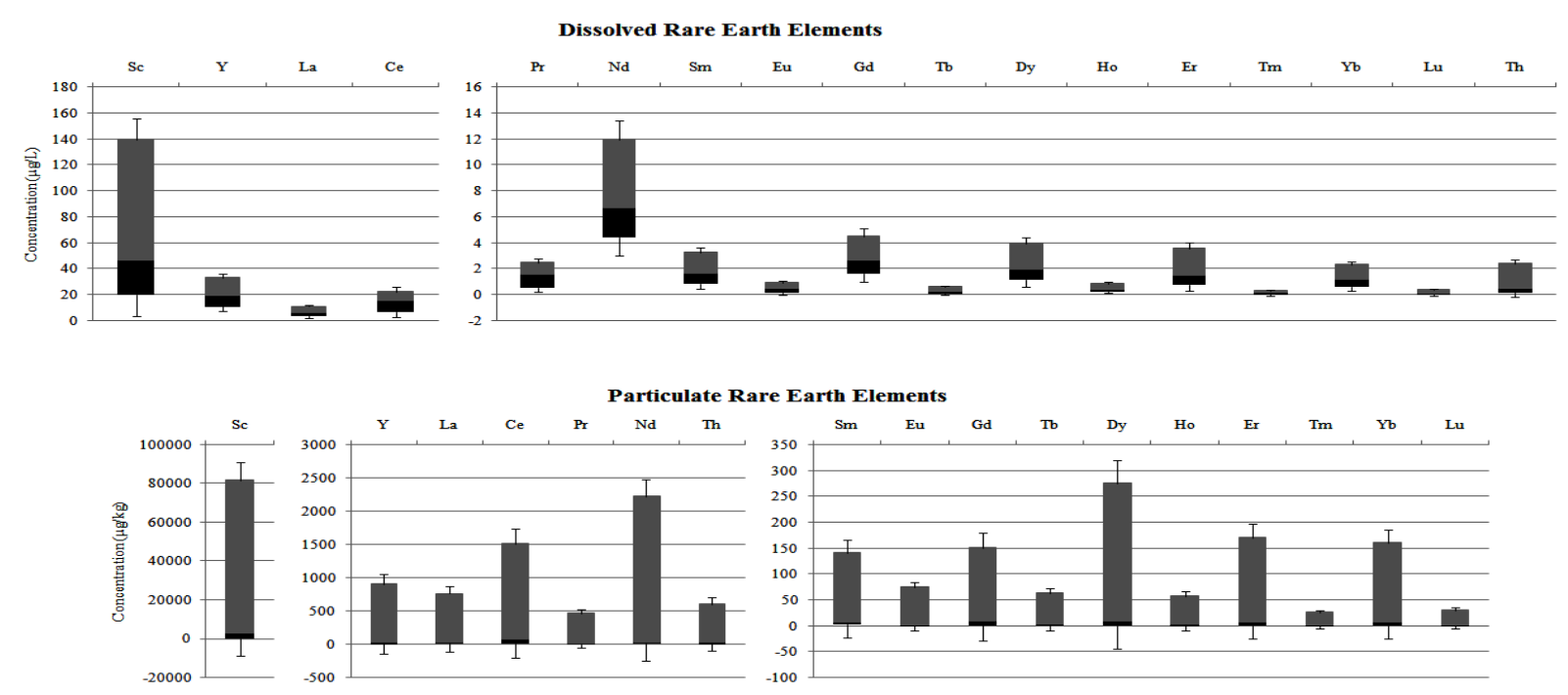

Fig.2. Concentration range of dissolved and particulate REEs in the Sulu and Celebes Seas

Overall, the median value indicated that most of the dissolved and particulate REEs data were distributed towards the minimum value of the data set. Dissolved and particulate Sc has the highest concentration among the REEs. Generally, minimum concentration of dissolved and particulate REEs was found east of Semporna and Tawau (ST46, ST48, ST52 and ST57), off Tanjung Labian (ST 29, ST30, ST31 and ST32) as well as at stations ST36, ST39, ST40, ST42 and ST43 which is in the vicinity of Darvel Bay. Maximum concentration of dissolved REEs were distributed largely at the surface layer (1m) of stations ST1, ST37 and ST41 whilst maximum particulate REEs were discovered at stations ST12, ST14, ST20 and ST26. These stations were identified to be the nearest stations to the mainland, and they received direct flush out from some major riverine such as Kinabatangan River, Paitan River, Sugut River and Segarna River. ST37 and ST41 were also the closest sampling stations to the 
mainland (Darvel Bay). On the whole, Pearson correlation showed that dissolved REEs was not significantly correlated with particulate REEs throughout all water layers.

\section{DISCUSSION}

The distribution of maximum concentration of REEs in the Sulu and Celebes Seas of Malaysian waters during the PMSE 09' expedition provides evidences on the contribution of REEs from the mainland into the seas. It is found that stations closest to the mainland of Sabah, Borneo as well as within the vicinity of riverine flushed outs have the highest concentration of REEs. Besides that, some of the sampling stations with the highest concentration of REEs were located in the Darvel Bay, the largest bay on the east of Sabah which received input from two main districts of Sabah namely Lahad Datu and Semporna. Vertical profiling of REEs concentration with depth did not show any distinctive vertical distribution pattern due to water samples were collected at the surface layer of the seas, i.e. less than 200m deep. According to [11], a marine basin is classified as a deep sea if its water layer is more than $200 \mathrm{~m}$. Besides that, in the surface water layer, the distribution of REEs tends to mix up and it will only show a stable reading once the deep water layer is reached $[11-12,25]$.

Pearson correlation matrix of all collected data proved the fact that dissolved and particulate REEs originated from different type of sources since they did not have significant correlation between themselves. Particulate lanthanides on the surface water $(1 \mathrm{~m})$ proved to have an anthropogenic behavior as they showed significant correlation with particulate $\mathrm{Cd}$ and $\mathrm{Pb}$, whereas dissolved REEs was found to be derived from geogenic sources. Similar to particulate lanthanides of the surface water, particulate REEs on the $50 \mathrm{~m}$ water layer also showed anthropogenic traces since they were significantly correlated with particulate $\mathrm{Zn}, \mathrm{Cd}$ and $\mathrm{Pb}$. In contrast, on the $25 \mathrm{~m}$ water layer, particulate REEs were proved to originate from geogenic sources whereas the dissolved REEs showed an anthropogenic behavior.

PCA was utilized on the raw dataset in order to delineate the compositional patterns between REEs and physical parameters. Besides that, PCA could identify factors that influence the distribution of rees throughout all water layers. The REEs were divided into two groups 
namely dissolved REEs (DR) and particulate REEs (PR). Four principal components (PCs) were acquired for DR, whereas five PCs were obtained for PR with eigenvalues larger than 1. The total variance in the data set sums up approximately $84.6 \%$ and $91.1 \%$ for DR and PR respectively (Table 1).

Table 1. Loadings of variables on the varimax rotated PCs for REEs during the PMSE 09'

\begin{tabular}{|c|c|c|c|c|c|c|c|c|c|}
\hline \multirow{2}{*}{ Variables } & \multicolumn{4}{|c|}{ DR } & \multicolumn{5}{|c|}{ PR } \\
\hline & VF1 & VF2 & VF3 & VF4 & VF1 & VF2 & VF3 & VF4 & VF5 \\
\hline $\mathrm{Sc}$ & -0.115 & 0.138 & -0.422 & -0.510 & 0.633 & 0.269 & -0.363 & -0.264 & 0.377 \\
\hline $\mathrm{Y}$ & 0.926 & 0.098 & -0.187 & -0.001 & 0.835 & -0.347 & 0.391 & -0.081 & -0.076 \\
\hline $\mathrm{La}$ & 0.856 & 0.167 & -0.247 & 0.030 & 0.858 & 0.148 & -0.259 & -0.172 & -0.022 \\
\hline $\mathrm{Ce}$ & 0.559 & -0.150 & -0.216 & 0.232 & 0.879 & 0.143 & -0.255 & -0.188 & 0.011 \\
\hline $\operatorname{Pr}$ & 0.841 & 0.143 & -0.283 & 0.042 & 0.607 & 0.185 & -0.339 & 0.687 & -0.062 \\
\hline $\mathrm{Nd}$ & 0.897 & 0.071 & -0.358 & 0.025 & 0.556 & 0.177 & -0.330 & 0.733 & -0.066 \\
\hline $\mathrm{Sm}$ & 0.901 & 0.061 & -0.241 & -0.008 & 0.879 & 0.175 & -0.296 & -0.214 & 0.078 \\
\hline $\mathrm{Eu}$ & 0.889 & 0.007 & -0.067 & 0.068 & 0.820 & 0.214 & -0.318 & -0.258 & 0.231 \\
\hline $\mathrm{Gd}$ & 0.909 & -0.010 & -0.287 & 0.026 & 0.953 & 0.005 & -0.108 & 0.224 & -0.049 \\
\hline $\mathrm{Tb}$ & 0.921 & 0.022 & 0.154 & -0.084 & 0.761 & 0.051 & -0.033 & 0.085 & -0.061 \\
\hline Dy & 0.923 & -0.037 & -0.104 & -0.090 & 0.833 & -0.174 & 0.137 & 0.468 & -0.087 \\
\hline Ho & 0.911 & 0.065 & 0.091 & -0.006 & 0.904 & -0.275 & 0.299 & -0.075 & -0.065 \\
\hline $\mathrm{Er}$ & 0.786 & 0.132 & -0.074 & -0.080 & 0.844 & -0.340 & 0.388 & -0.045 & -0.066 \\
\hline $\mathrm{Tm}$ & 0.841 & 0.044 & 0.308 & -0.078 & 0.933 & -0.199 & 0.192 & -0.062 & -0.076 \\
\hline $\mathrm{Yb}$ & 0.874 & -0.012 & 0.102 & 0.092 & 0.836 & -0.347 & 0.398 & -0.081 & -0.067 \\
\hline $\mathrm{Lu}$ & 0.771 & 0.026 & 0.376 & -0.082 & 0.925 & -0.185 & 0.191 & -0.048 & -0.048 \\
\hline Th & 0.516 & 0.154 & 0.660 & 0.112 & 0.901 & 0.062 & -0.113 & -0.241 & 0.160 \\
\hline Conductivity & -0.124 & -0.908 & -0.303 & 0.037 & 0.079 & 0.510 & 0.666 & 0.226 & 0.476 \\
\hline DO & -0.341 & 0.931 & -0.062 & 0.043 & -0.220 & -0.831 & -0.508 & -0.016 & 0.021 \\
\hline Salinity & -0.701 & 0.076 & -0.534 & 0.116 & -0.219 & -0.509 & 0.211 & 0.303 & 0.722 \\
\hline Temperature & 0.451 & -0.860 & 0.160 & -0.060 & 0.245 & 0.857 & 0.418 & -0.044 & -0.159 \\
\hline SPM & -0.001 & 0.028 & -0.082 & 0.863 & -0.525 & -0.019 & 0.247 & -0.005 & -0.231 \\
\hline Eigenvalue & 12.16 & 2.60 & 1.82 & 1.14 & 12.11 & 2.74 & 2.33 & 1.76 & 1.10 \\
\hline Variability (\%) & 55.28 & 11.80 & 8.26 & 5.19 & 55.06 & 12.47 & 10.58 & 8.02 & 5.01 \\
\hline Cumulative \% & 55.28 & 67.08 & 75.34 & 80.53 & 55.06 & 67.53 & 78.11 & 86.13 & 91.14 \\
\hline
\end{tabular}


PCA for DR (Table 2) showed that VF1 describes 55.28\% of the total variance amongst the four VFs. A strong positive loadings on Y, La, Pr, Nd, Sm, Eu, Gd, Tb, Dy, Ho, Er, Tm, Yb and $\mathrm{Lu}$, moderate positive loadings on $\mathrm{Ce}$ and $\mathrm{Th}$ as well as moderate negative loadings on salinity. Based on the raw dataset, maximum concentration of dissolved REEs was generally found on the surface waters whereas minimum concentration was recorded at the deepest water layer. In contrast to dissolved REEs, salinity was increased with the water depth which explains the inverse relationship between dissolved REEs and salinity in the Sulu and Celebes Seas. Theoretically, salinity does increase with depth due to high density of the seawater as well as the intrusion of freshwater on the seawater surface layer. The open ocean contains approximately $1021 \mathrm{~kg} / \mathrm{m}^{3}$ of seawater density whereas in deep seawater (at a pressure of $10,000 \mathrm{dbar}$ ), the density normally increased to $1070 \mathrm{~kg} / \mathrm{m}^{3}$ [26]. On the surface water of the ocean, the intrusion of freshwater into the seawater reduces the density of the seawater as the density of freshwater is approximately $1000 \mathrm{~kg} / \mathrm{m}^{3}$. VF2 elucidates $11.80 \%$ of the total variance with strong positive loadings on DO and strong negative loadings on conductivity and temperature. In the seawater, at high temperature, DO decreased due to low dissolution of oxygen in the water and high temperature tends to release oxygen into the atmosphere [27]. In the meantime, oxygen has to compete with salt ions for the sorption site with water molecules in seawater [28-30]. Besides that, VF3 enlightens $8.26 \%$ of the total variance with moderate positive and negative loadings on Th and salinity correspondingly. VF4 describes $5.19 \%$ of the total variance, showing strong positive loadings on SPM and moderate negative loadings on Sc. Based on VF3 and VF4, Th has inverse relationship with salinity while Sc has the same relationship with SPM.

In PCA for PR (Table 1), VF1 enlighten 55.06\% of the total variance shows strong and moderate positive loadings on all particulate REEs and moderate negative loadings on SPM. This factor proved that all particulate REEs have inverse relationship with SPM. VF2 describes $12.47 \%$ of the total variance with strong positive and negative loadings on temperature and DO respectively. Similar to VF1 of DR, the positive and negative loadings explain the inverse relationship between temperature and DO in the water column. In the meantime, VF3, VF4 and VF5 explain $10.58 \%, 8.02 \%$ and $5.01 \%$ of the total variance 
correspondingly and show the moderate positive loadings on conductivity, $\mathrm{Nd}$ and salinity. Normalization of REEs in the present study was carried out against the North Pacific Deep Water (NPDW) [31] and Post-Archean Australian Sedimentary rocks (PAAS) [32] in order to discuss the fractionation of REEs. NPDW was selected as the normalizer due to similarity in composition based on the water masses rather than shale. The NPDW is believed to be the major supplier for the Southeast Asian basin, whereas PAAS is the representative for the upper continental crust.

In the water column, the correlation between dissolved Ce with the water depth is commonly defined by the $\mathrm{Ce} / \mathrm{Ce}$ * anomaly normalized against PAAS. The anomaly is calculated as:

$\mathrm{Ce} / \mathrm{Ce} *=2[\mathrm{Ce}] /([\mathrm{La}]+[\mathrm{Pr}])$

where [ ]: PAAS normalized value.

If the anomaly pointed out a value less than 1, indicated a depletion of Ce relative to LREEs, i.e: $\mathrm{La}$, $\mathrm{Pr}$ and $\mathrm{Nd}$. The $\mathrm{Ce} / \mathrm{Ce}^{*}$ anomaly values calculated in the present study were larger than 1, which agreed with the shallow water column. On the surface water column, the trivalent $\mathrm{Ce}(\mathrm{Ce}[\mathrm{III}])$ is easily oxidized to tetravalent $\mathrm{Ce}(\mathrm{Ce}[\mathrm{IV}])$ which is insoluble [13-14]. Even though $\mathrm{Ce} / \mathrm{Ce}^{*}$ anomalies found in the water samples were larger than 1 , the median value of $\mathrm{Ce} / \mathrm{Ce}^{*}$ anomaly in the deepest layer, i.e. $100 \mathrm{~m}$ showed a consistent range of dataset compared to other water layer (Fig. 3).

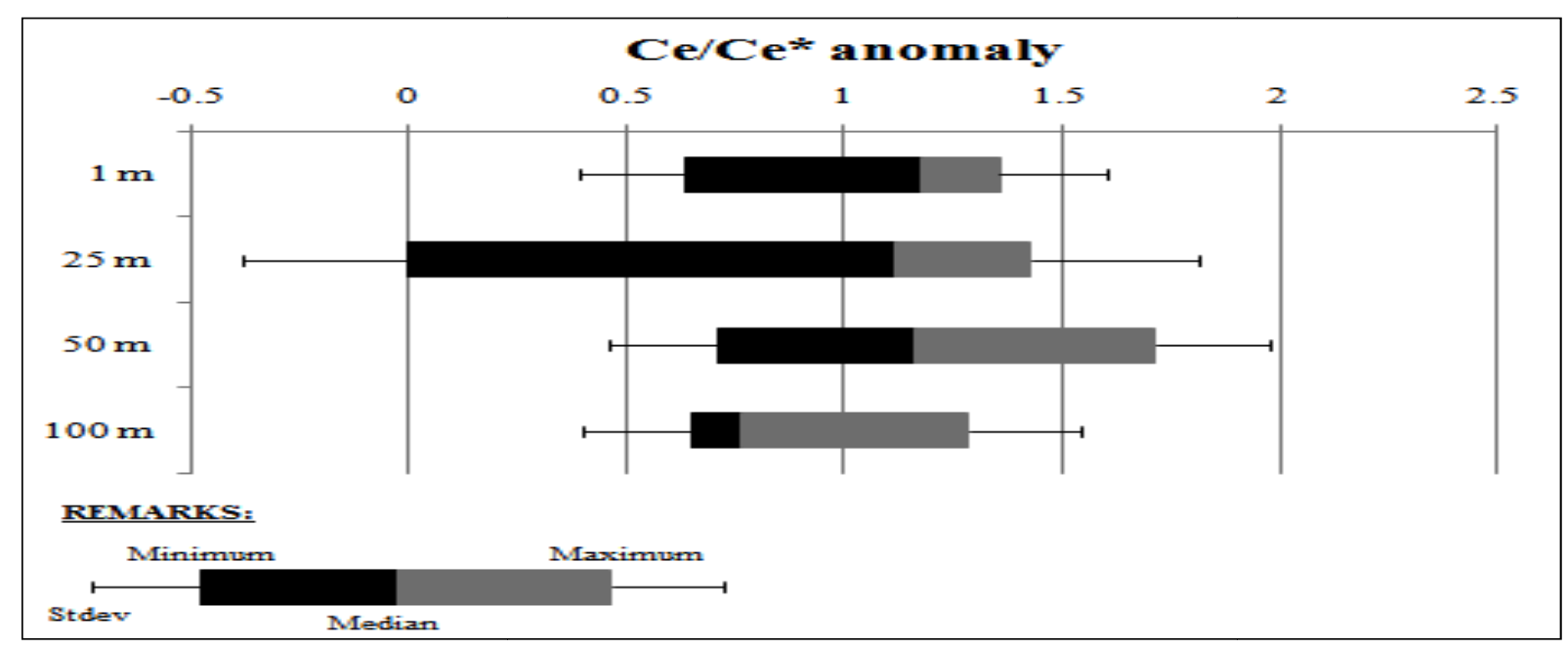

Fig.3. Boxplot of $\mathrm{Ce} / \mathrm{Ce} *$ anomaly

Additionally, the median of $\mathrm{Ce} / \mathrm{Ce}^{*}$ anomaly decreases with the increase in water depth. The decreasing of $\mathrm{Ce} / \mathrm{Ce}^{*}$ anomaly value is not caused by the decreasing of $\mathrm{Ce}$ oxidation rate. 
However, it was due to regeneration of La and Pr to the water column corresponding to the constant concentration of $\mathrm{Ce}$; plus significant correlation between the concentrations of $\mathrm{Ce}$ with DO. This finding is similar to other research done in the Sulu and Celebes Seas by [13-14]. Fig. 4 shows the pattern of REEs normalized against NPDW.

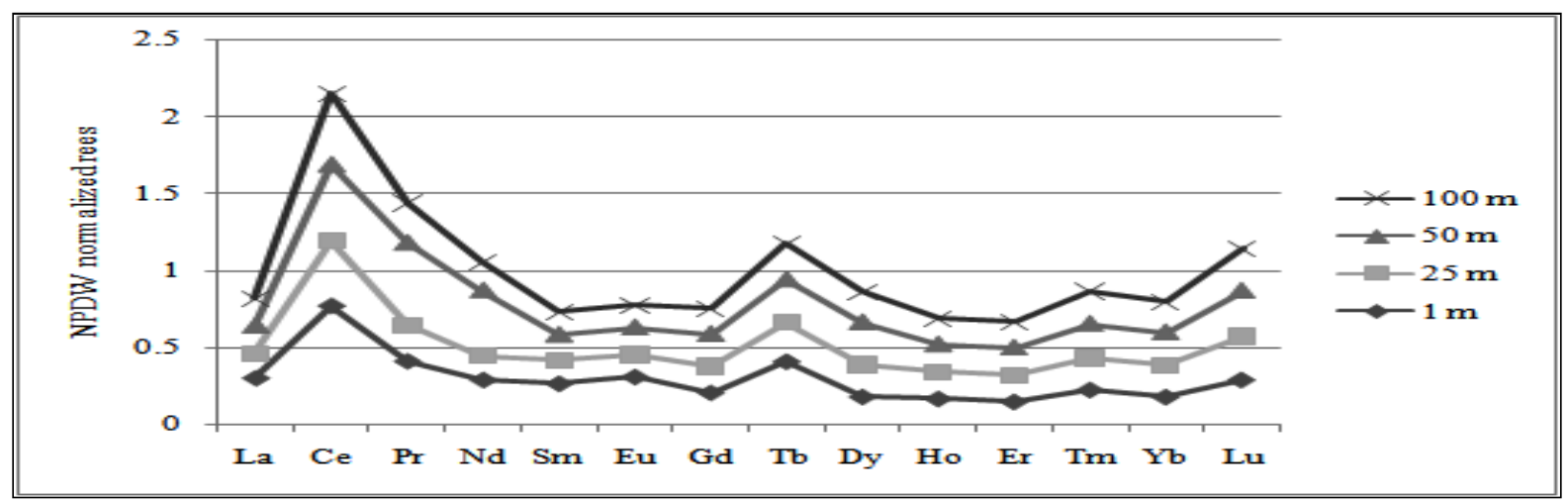

Fig.4. NPDW normalized REEs in the Sulu and Celebes Seas of Malaysian waters

Based on Fig. 5, Ce is positively related to $\mathrm{La}$ and $\mathrm{Pr}$ which indicates that $\mathrm{Ce}$ is enriched compared to NPDW. The REEs normalized against NPDW increased with the increase in water depth. The normalized patterns also clearly shows depression of Gd which is similar to the characteristics of South China Sea, but on the $50 \mathrm{~m}$ and $100 \mathrm{~m}$ water layers, the REEs normalized patterns shows mild depression of Gd compared to $1 \mathrm{~m}$ and $25 \mathrm{~m}$ water layers (Fig. 5). Thus, it is apparent that the surface water of the seas under study is derived from the South China Sea which is similar to the finding of [13]. In the meantime, on the deeper water layers, i.e. $50 \mathrm{~m}$ and $100 \mathrm{~m}$, mild depression of $\mathrm{Gd}$ indicates less contribution of the South China Sea and intrusion of local river drainage dominates the deeper water of these seas. Besides that, comparison of REEs normalized NPDW patterns for the present study with REEs normalized NPDW of the Chao Praya River [13] in Fig. 5 shows no similarity in the normalized patterns. Thus, it can be concluded that REEs in the water column of Sulu and Celebes Seas are not influenced by Asian rivers but it is influenced by local river drainage such as Borneo Island, Indonesia and Philippine archipelagos as well as other volcanic islands around the area. 

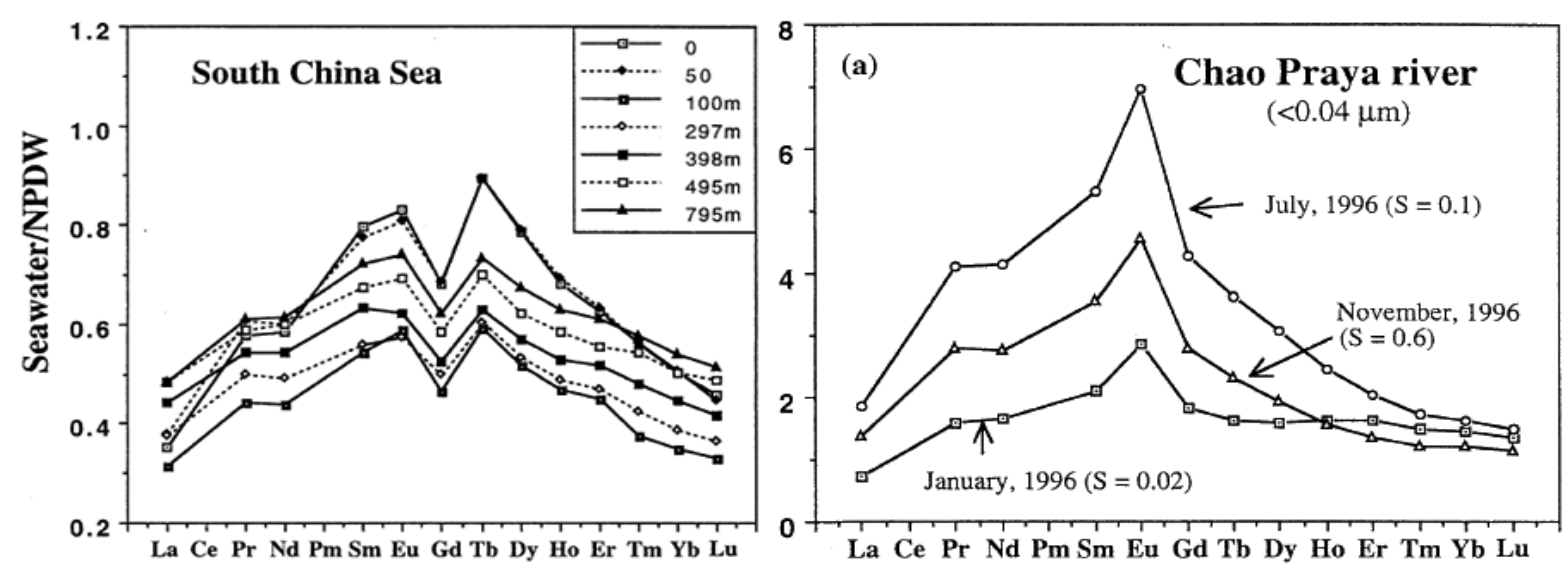

Fig.5. NPDW normalized pattern of the South China Sea and Chao Praya River

\section{CONCLUSION}

Measurements of REEs in the Sulu and Celebes Seas of Malaysian waters during PMSE 09' expedition proved that the shallow sills of Sulu Sea have isolated these seas from South China Sea. Gd depression on the NPDW normalized patterns. For the present study showed that South China Sea does influence the surface water of the study area but the impact lessens towards the deeper water layers. Additionally, NPDW normalized patterns also showed no influence of Asian rivers namely Chao Praya River but local river drainage of the Borneo Island and other volcanic islands around the area namely Indonesia and the Philippine archipelagos may influence this pattern. PAAS normalized REEs give an idea on $\mathrm{Ce} / \mathrm{Ce}$ * anomaly vertical profiling because on surface water, the oxidation of Ce was high. The anomaly decreased with the increasing in water depth due to regeneration of La and Pr.

In the meantime, vertical profiling of rees in the Sulu and Celebes Seas off Malaysian coasts showed no specific patterns as the $100 \mathrm{~m}$ of water layer is still classified as surface water for the Sulu and Celebes Seas. Spatial distribution demonstrated high concentration of elements on the tip of Borneo Island particularly in between the two Borneo 'horns' and surrounding islands. High concentration of elements was also discovered at stations that received direct flush out from Kinabatangan, Sugut and Segarna Rivers as well as stations in the vicinity of Darvel Bay which were closest to the mainland of Borneo. Pearson correlation conducted pointed out that particulate lanthanides on the $1 \mathrm{~m}$ water layer and dissolved REEs on the $25 \mathrm{~m}$ water layer were derived from anthropogenic sources due to significant correlation with 
anthropogenic metals namely $\mathrm{Cd}, \mathrm{Pb}, \mathrm{Zn}, \mathrm{Cu}$ and $\mathrm{Fe}$. On the other hand, dissolved REEs originated from geogenic sources as they showed significant correlation with abundance metals in the upper continental crust.

Statistical analysis of PCA revealed that DO, temperature, salinity and conductivity is closely related. Additionally, PCA showed inverse relationship between dissolved REEs with salinity in depth. The decreasing of REE's concentration with the increasing of salinity and water depth was due to the competition of REEs ions with salt ions for binding sites.

In a nutshell, the collected hydrographic data and measured REEs concentration proved that anthropogenic input from land-based and physico-chemical characteristics of both seas off Malaysian coasts reflect the health and productivity of the Coral Triangle Initiative area within Malaysian waters.

\section{ACKNOWLEDGEMENTS}

Ministry of Science, Technology and Innovation Malaysia (MOSTI) and National Oceanography Directorate (NOD) funded this research through a research grant (grant numbers: 58006) in collaboration with Royal Malaysian Navy (RMN). The authors would like to thank MOSTI and NOD for the research grant; Pusat Hidrografi Nasional (PHN) and RMN for providing the cruise ship KD Perantau as well as Institute of Oceanography and Environment, Universiti Malaysia Terengganu for assistance given during sampling and analysis. Thank you to the Commanding Officer and crew of KD Perantau for their assistance during the expedition.

\section{REFERENCES}

[1] Connelly N. G., Damnus T., Hartshorn R. M., Hutton A. T. Nomenclature of inorganic chemistry: IUPAC recommendations 2005. Cambridge: Royal Society of Chemistry Publishing, 2005

[2] Lin R, Howard B H, Roth E A, Bank T L, Granite E J, Soong Y. Enrichment of rare earth elements from coal and coal by-products by physical separations. Fuel, 2017, 200:506-520

[3] Ippolito N M, Innocenzi V, De Michelis I, Medici F, Vegliò F. Rare earth elements 
recovery from fluorescent lamps: A new thermal pretreatment to improve the efficiency of the hydrometallurgical process. Journal of Cleaner Production, 2017, 153:287-298

[4] Kulaksız S, Bau M. Contrasting behaviour of anthropogenic gadolinium and natural rare earth elements in estuaries and the gadolinium input into the North Sea. Earth and Planetary Science Letters, 2007, 260(1):361-271

[5] Duvert C, Cendón D I, Raiber M, Seidel J L, Cox M E. Seasonal and spatial variations in rare earth elements to identify inter-aquifer linkages and recharge processes in an Australian catchment. Chemical Geology, 2015, 396:83-97

[6] Agnan Y, Séjalon-Delmas N, Probst A. Origin and distribution of rare earth elements in various lichen and moss species over the last century in France. Science of the Total Environment, 2014, 487:1-12

[7] Delgado J, Pérez-López R, Galván L, Nieto J M, Boski T. Enrichment of rare earth elements as environmental tracers of contamination by acid mine drainage in salt marshes: A new perspective. Marine Pollution Bulletin, 2012, 64(9):1799-1808

[8] Xiang G, Jiang Z, He M, Hu B. Direct determination of trace rare earth elements in ancient porcelain samples with slurry sampling electrothermal vaporization inductively coupled plasma mass spectrometry. Spectrochimica Acta Part B: Atomic Spectroscopy, 2005, 60(9):1342-1348

[9] Zhu Z, Liu C Q, Wang Z L, Liu X, Li J. Rare earth elements concentrations and speciation in rainwater from Guiyang, an acid rain impacted zone of Southwest China. Chemical Geology, 2016, 442:23-34

[10] Varekamp J C. The chemical composition and evolution of volcanic lakes. In D. Rouwet, B. Christenson, F. Tassi, \& J. Vandemeulebrouck (Eds.), Volcanic lakes. Berlin: Springer, 2004, pp. 93-123

[11] Asante K A, Agusa T, Kubota R, Mochizuki H, Ramu K, Nishida S, Ohta S, Yeh H M, Subramanian A, Tanabe S. Trace elements and stable isotope ratios ( $\delta 13 \mathrm{C}$ and $\delta 15 \mathrm{~N})$ in fish from deep-waters of the Sulu Sea and the Celebes Sea. Marine Pollution Bulletin, 2010, 60(9):1560-1570

[12] Norisuye K, Ezoe M, Nakatsuka S, Umetani S, Sohrin Y. Distribution of bioactive trace 
metals (Fe, Co, Ni, Cu, Zn and Cd) in the Sulu Sea and its adjacent seas. Deep Sea Research Part II: Topical Studies in Oceanography, 2007, 54(1):14-37

[13] Nozaki Y, Alibo D S, Amakawa H, Gamo T, Hasumoto H. Dissolved rare earth elements and hydrography in the Sulu Sea. Geochimica et Cosmochimica Acta, 1999, 63(15):2171-2181

[14] Obata H, Doi T, Hongo Y, Alibo D S, Minami H, Kato Y, Maruo M. Manganese, cerium and iron in the Sulu, Celebes and Philippine Seas. Deep Sea Research Part II: Topical Studies in Oceanography, 2007, 54(1):38-49

[15] Adiana G, Shazili N A, Marinah M A, Bidai J. Effects of northeast monsoon on trace metal distribution in the South China Sea off Peninsular Malaysia. Environmental Monitoring and Assessment, 2014, 186(1):421-431

[16] Adiana G, Shazili N A M, Marinah M A. Cadmium, manganese and lead distribution in the South China Sea off the South Terengganu Coast, Malaysia during post-monsoon and pre-monsoon. Journal of Sustainability Science and Management, 2011, 6(2):181-192

[17] Bidai J, Adiana G, Shazili N A. Particle sizes effect of the elements in the South China Sea sediment off Pahang coastal during the Northeast monsoon (pre-) and the Southwest monsoon (post-) periods. Environmental Earth Sciences, 2016, 75(7):614

[18] William W H T. Distribution of dissolved and particulate trace metals in Terengganu River estuary. Master thesis, Terengganu: Universiti Malaysia Terengganu, 2008

[19] Bowles K C, Apte S C, Batley G E, Hales L T, Rogers N J. A rapid Chelex column method for the determination of metal speciation in natural waters. Analytica Chimica Acta, 2006, 558(1):237-245

[20] Chabukdhara M, Nema A K. Assessment of heavy metal contamination in Hindon River sediments: a chemometric and geochemical approach. Chemosphere, 2012, 87(8):945-953

[21] Juahir H, Zain S M, Yusoff M K, Hanidza T T, Armi A M, Toriman M E, Mokhtar M. Spatial water quality assessment of Langat River Basin (Malaysia) using environmetric techniques. Environmental Monitoring and Assessment, 2011, 173(1-4):625-641

[22] Juahir H, Zain S M, Aris A Z, Yusoff M K, Mokhtar M B. Spatial assessment of Langat river water quality using chemometrics. Journal of Environmental Monitoring, 2010, 
12(1):287-295

[23] Reghunath R, Murthy T S, Raghavan B R. The utility of multivariate statistical techniques in hydrogeochemical studies: An example from Karnataka, India. Water Research, 2002, 36(10):2437-2442

[24] Liu C W, Lin K H, Kuo Y M. Application of factor analysis in the assessment of groundwater quality in a Blackfoot disease area in Taiwan. Science of the Total Environment, 2003, 313(1):77-89

[25] Calvert S E, Pedersen T F, Thunell R C. Geochemistry of the surface sediments of the Sulu and South China Seas. Marine Geology, 1993, 114(3-4):207217-11231

[26] Brown W S. Physical properties of seawater. In M. R. Dhanak, \& N. I. Xiros (Eds.), Springer Handbook of Ocean Engineering. Cham: Springer 2016, pp. 101-110

[27] Manasrah R, Raheed M, Badran M I. Relationships between water temperature, nutrients and dissolved oxygen in the northern Gulf of Aqaba, Red Sea. Oceanologia, 2006, 48(2):237-354

[28] Rasheed M, Badran M I, Huettel M. Particulate matter filtration and seasonal nutrient dynamics in permeable carbonate and silicate sands of the Gulf of Aqaba, Red Sea. Coral Reefs, 2003, 22(2):167-177

[29] Wheeler P A, Huyer A, Fleischbein J. Cold halocline, increased nutrients and higher chlorophyll off Oregon in 2002. Geophysical Research Letters, 2003, 30(15):1-4

[30] Badran M I. Dissolved oxygen, chlorophyll a and nutrients: Seasonal cycles in waters of the Gulf of Aquaba, Red Sea. Aquatic Ecosystem Health and Management, 2001, 4(2):139-150 [31] Alibo D S, Nozaki Y. Rare earth elements in seawater: particle association, shale-normalization, and Ce oxidation. Geochimica et Cosmochimica Acta, 1999, 63(3):363-372

[32] Taylor S. R., McLennan S. M. The continental crust: Its composition and evolution. An Examination of the geochemical record preserved in sedimentary rocks. California: Blackwell Scientific Publications, 1985. 
How to cite this article:

Adiana G, Juahir H, Shazili NAM, Joseph B, Ireana Yusra AF. Variation of rare earth elements (REEs) in the Sulu and Celebes Seas of Malaysian waters during PMSE 09' Expedition using analytical and chemometric techniques. J. Fundam. Appl. Sci., 2017, 9(2S), 413-429. 